\title{
ELF: sharing the scientific expertise of the ERS with the public
}

\section{Public voice of the ERS}

The European Lung Foundation (ELF) is the public voice of the European Respiratory Society (ERS). It was established to serve the European Community by sharing the scientific expertise of the ERS with the public.

The ELF has been involved in several projects, such as the spirometry tent and the Small White Book "Lung Health in Europe: Facts and Figures", which have increased public awareness and knowledge about respiratory diseases and their impact on individuals and on Europe as a whole. However, as was evident from the omission of respiratory diseases from the preliminary version of the European Research Framework Programme (FP7), these diseases still do not have a high-enough profile in the public and, hence, political arena. In addition, the ELF is aware that there are many sources of information available on respiratory diseases that the general public and patients are able to easily access that may be misleading or inaccurate.

With these points in mind, the ELF has developed some new strategies to provide reliable respiratory information to a wider audience across Europe. These include a new website and a "Lung information" patient and general public education factsheet series in Breathe, the first of which you will find at the back of this issue.

\section{ELF website}

The ELF website went live at the beginning of January, and can be found at www.europeanlung-foundation.org Briefly, the website comprises three main sections: facts about normal lung function; information concerning lung diseases; and data on the risk factors that influence lung health. The site is aimed at the general public, patients and politicians.

Specific features of the ELF website include:

- detailed images and movies showing normal lung structure and function

- comprehensive facts and figures on asthma, COPD, lung cancer, pneumonia, tuberculosis, cystic fibrosis, sleep apnoea and interstitial lung diseases

- EU actions concerning tobacco, the environment, and diet and nutrition

- information and reliable links concerning hot issues and topics, such as avian flu

- testimonies from patients about their disease

- chat forum capabilities

- reliable and trusted links to other lung associations throughout Europe

- calendar highlighting important events in Europe for patients and politicians

We hope that you will go and view this new site. We also hope that you will find that it is a benefit to you in your practice and a resource that you can use for your patients. As the ERS will provide the resources for the site and review any content, you will be able to rely on the site to provide the information that you want your patients to read. You and your patients can also sign up to our database to receive an e-newsletter and regular information.

In addition to the English-language site, seven further language sites (French, German, Spanish, Italian, Russian, Polish and Greek) will be developed during 2006, to allow the dissemination of information throughout Europe.

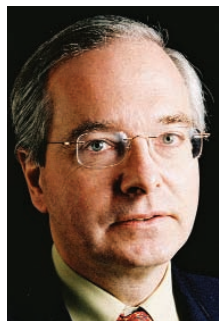

Laurent P. Nicod

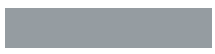

ELFChair

Director

Clinic and Policlinic of Pneumology Inselspital

Bern

Switzerland 
Please go to page 295 to see the first factsheet on normal lung function.

\section{ELF factsheets}

The new factsheet series, which can be found in the back of this issue, has been designed to complement the website. The factsheets will be included in every issue of Breathe and will cover a different topic each time. It is hoped that recipients of the journal will cut out, copy and offer the information to their patients. After distribution in Breathe, the factsheets will be posted onto the ERS website and then translated into the languages of the website. Therefore, more copies can be obtained in this manner.

We hope that the new website and the factsheet series will prove a benefit to you and your patients. We would also like to ask any readers of Breathe to visit the ELF website and make comments or suggestions.

For further information on the ELF please contact the Manager at elf@ersnet.org

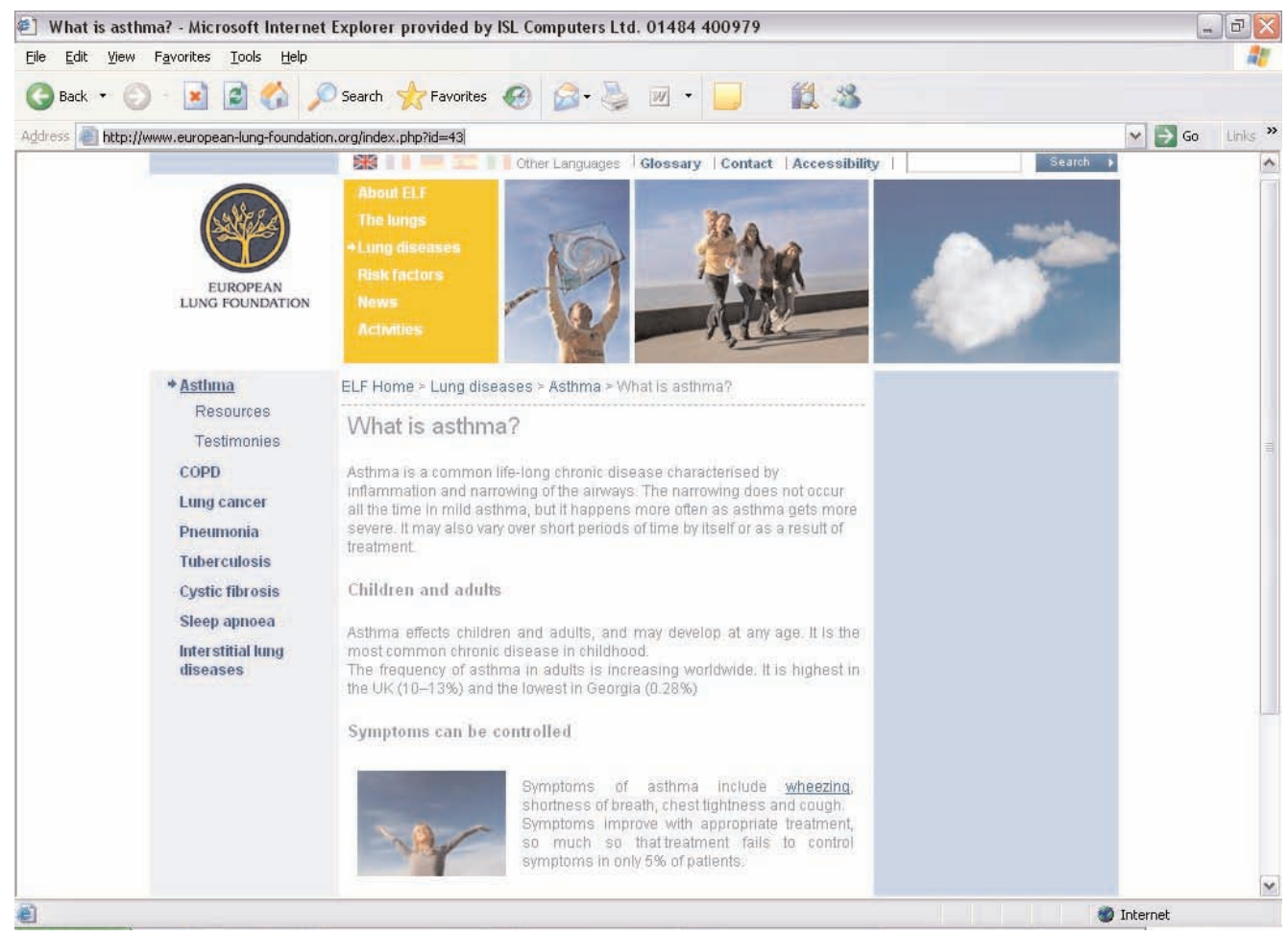

